\title{
Associations between SARS-CoV-2 and bacteria in the hospital environment
}

Clarisse Marotz

Pedro Belda-Ferre

Farhana Ali

Promi Das

Shi Huang

Kalen Cantrell

Lingjing Jiang

Cameron Martino

Rachel E. Diner

Gibraan Rahman

Daniel McDonald

George Armstrong

Sho Kodera

Sonya Donato

Gertrude Ecklu-Mensah

Neil Gottel

Mariana C. Salas Garcia

Leslie Y. Chiang

Rodolfo A. Salido

Justin P. Shaffer

MacKenzie Bryant

Karenina Sanders

Greg Humphrey

Gail Ackermann

Niina Haiminen

Kristen L. Beck

Ho-Cheol Kim

Anna Paola Carrieri

Laxmi Parida

Yoshiki Vázquez-Baeza

Francesca J. Torriani

Rob Knight

Jack Gilbert

Daniel A. Sweeney

Sarah M. Allard 


\section{Video Byte}

Keywords: built environment, SARS-CoV-2, 16S rRNA, Microbiome, COVID-19, hospital, virus, bacteria, Rothia, fomite, surface contamination, health care, health care workers, patient

Posted Date: October 13th, 2021

DOI: https://doi.org/10.21203/rs.3.rs-967789/v1

License: (c) (i) This work is licensed under a Creative Commons Attribution 4.0 International License. Read Full License 


\section{Abstract}

SARS-CoV-2 is the notorious virus responsible for the COVID-19 pandemic. Like other viruses, it coexists with a multitude of other microorganisms that could influence our susceptibility to infection. Thus, identifying associations between bacteria and SARS-CoV-2 could lend critical insight for the development of strategies for COVID-19 prevention and treatment. To meet this need, researchers recently characterized the microbial communities associated with COVID-19 patients, health care providers, and indoor surfaces in the hospital environment using $16 \mathrm{~S}$ rRNA sequencing. They found SARS-CoV-2 RNA on $16 \%$ of the surfaces in COVID-19 patient rooms, with the highest prevalence in floor samples and lower prevalence on bed rails. SARS-CoV-2-positive samples had higher bacterial diversity than SARS-CoV-2negative samples. Interestingly, bacteria in the genus Rothia were commonly found in the samples containing SARS-CoV-2, suggesting the existence of an association between these microorganisms. Rothia species are common members of the human oral microbiome but can also invade the gastrointestinal tract and are associated with cardiovascular disease. These findings suggest that Rothia could be used as an indicator of individuals with increased risk of COVID-19 complications and may facilitate the development of effective methods to reduce SARS-CoV-2 virulence. 